\title{
Metaphysical Foundations of Theistic Argumentation
}

\section{Aleksandr Kulieshov ${ }^{1}$}

${ }^{1}$ Cherkasy State Technological University

460 Shevchenko Boulevard, 18006, Cherkasy, Ukraine

DOI: $10.22178 /$ pos.69-1

LCC Subject Category: BD95-131

Received 20.03.2021

Accepted 27.04.2021

Published online 30.04.2021

Corresponding Author:

klshv2014@gmail.com

(C) 2021 The Author. This article is licensed under a Creative Commons Attribution 4.0 License @ (1)
Abstract. The proofs of God's existence is the subject matter of the article. Four main types of proofs are analyzed: cosmological, teleological, ontological and moral. It is argued that there is a general scheme of theistic reasoning present in all four types of proving. The principal feature of this scheme lies in recognizing a ground of everything existing which goes beyond the material (or natural) world. Possible naturalistic arguments excluding a non-material, supernatural foundation of the world are also analyzed. The objections to naturalistic arguments are formulated, making it possible to assert that the natural world cannot be explained from itself. Nor it can be explained from its physical (or natural) part. At the same time, the material world needs an explanation. To meet this need, the extended direct theistic arguments are formulated in the article. They begin with the fact of there being something and include two aspects of theistic argumentation: one is to establish the existence of immaterial foundation of the natural world; another is to demonstrate that this immaterial foundation may be identified with the world subject omnipotent, omniscient, all-good, immaterial rational being which mainly corresponds to God of theistic religions. The conclusion is made that the thinkability and rationality of the idea of God is provable. One can argue that the idea of God more rationally explains the world. Moreover, it is evident that theism is rational, naturalism (as the principle of the general explanation of everything) is irrational. But the question remains how rational the world is.

Keywords: God; theistic arguments; naturalistic arguments; grounding; the material world foundation; the function of choice; the world subject; metaphysics.

\section{INTRODUCTION}

Proving God's existence is one of the oldest intellectual games played by civilized humankind. Many philosophers and theologians have tried their hand at this game. However, the practical results of their efforts are insignificant. Typically, the evidence found does not convince nonbelievers. The most apparent denials do not dissuade believers. The existence of God remains a matter of faith. It seems that any positive knowledge is impossible here.

Nevertheless, the discussion is not fading and seems to be even intensifying. Why is this happening? It is unlikely that both proofs and refutations of the existence of God are just exercises for the mind. The issue under discussion is too severe. One can assume that people have an inescapable need for a holistic, understandable, sys- tematic, complete, and comfortable mental model of the world. Such a model is to be, in a sense, independent of empirical data. And such a model must either include God (or something Divine) or exclude it.

It seems that the philosophical problem of God is not a problem of trusting any religion; it is not a problem of faith. This is the problem of integrity in our understanding of the world. Without clarifying our attitude to the idea of God (accepting it or denying), we leave the natural world as a whole as something otherworldly for ourselves; we mystify it to a large extent. If our complete understanding of the world is impossible, then is the concept of God the best possible explanation? If our understanding of the world is possible, then is the recognition of God's existence true? And is it possible, in this case, to explain the world without resorting to such a recognition? 
In the history of philosophy (including philosophical theology), many ways have been developed to prove the existence of God. The very fact that there are many proofs invokes some doubts about their effectiveness and raises the question of their unification. The literature on the topic is boundless. Since our article is not bibliographic and does not relate to the history of ideas, careful analysis of this literature would have distracted us from our goal. (For a rather detailed summary of the main types of theistic argumentation in theology and philosophy, see [10]).

As a basis for reasoning, four types of proofs are chosen: cosmological, teleological, ontological, and moral. A substantial general survey of the cosmological proof can be found in [7], teleological - in [6], ontological - in [5], moral - in [2]. Of the relatively recent studies in English on the first type of proofs, one should pay attention to [1], on the second - to [9], on the third - to [4], on the fourth - to [8].

In its general formulation, the cosmological argument comes down to the statement that the dependencies observed in the universe indicate the existence of "a first cause, sustaining cause, unmoved mover, necessary being, or personal being (God)" [7]. The teleological argument can be taken in this formulation: "Some phenomena within nature exhibit such exquisiteness of structure, function or interconnectedness that many people have found it natural to see a deliberative and directive mind behind those phenomena. ...The resultant theistic arguments, in their various logical forms, share a focus on a plan, purpose, intention, and design, and are thus classified as teleological arguments (or, frequently, as arguments from or to design)" [6]. The ontological argument in its general form can be taken like this: it is an argument which makes an inference from the concept of God (its semantics or modality) to God's existence, in other words - "from premises which are supposed to derive from some source other than observation of the world" to "the conclusion that God exists" [5]. Finally, the moral argument is acceptable to understand as an argument "that reasons from some feature of morality or the moral life to the existence of God, usually understood as a morally good creator of the universe" [2].

The article aims to justify the thinkability of theistic argumentation and, on the contrary, the unthinkability of counter-arguments, those offering the alternatives to the theistic version of the world understanding. For this, a unified formulation of the theistic argument will be given, combining the four formulated basic types of God's existence proofs. All logically possible alternatives to this argument will be formulated. It will be demonstrated that these alternative arguments don't work. Finally, the metaphysically extended theistic argument will be presented, and its relation to the common traits of the idea of God in theistic religions will be defined.

\section{RESULTS AND DISCUSSION}

Any proof of God's existence includes two objectives, similar to those distinguished by William L. Rowe within the cosmological argument, "one to establish the existence of a first cause or necessary being, the other that this necessary being is God" [7]. In some (non-theistic) religions, the first objective is self-sufficient. Considering the overall scheme of proofs for the existence of God, one should have in mind the sequence of these objectives.

All such proofs will be called theistic arguments. The general scheme of theistic arguments is as follows:

1. Everything that exists (besides, perhaps, the ground of everything, if there is any) has the outside ground of its existence. Thus, everything that exists is grounded. (An object (that is, something that exists) should be called grounded if it exists only under the condition of another object existence, the latter being called it's ground. Note that the relationship of grounding is generally nonreflective, asymmetric and transitive.)

2. There are some clear evidence of existing objects of a particular type.

3 . These evidence point to a ground that goes beyond the material (or natural) world.

4. The stated ground is ultimate; that is, it has no further ground.

5. Under its groundlessness and point 1, the ultimate ground is the ground of all that exists.

6. Consequently, the ultimate ground is the immaterial (by point 3) ground of the material (or natural) world.

7. Such a ground of everything in the world is God - omnipotent (by being the foundation of everything), omniscient (for the same reason and by its immateriality) and all-good (by creating 
the human moral creature) being, the immaterial Creator of the world.

The stated evidence of experience can be divided into external and internal. External evidence are the natural dependences between the material world phenomena (for example, causal) and the expediency of phenomena in the material world this is the basis of the cosmological and teleological arguments. Internal evidences are the concept of God and values (primarily moral) in the human mind. Ontological and moral arguments are based on this.

Point 2 of the scheme shown is not objectionable since we deal here with the evidence of experience. Points 5, 6, 7 are conclusions based on the previous points. Points 1, 3, 4 are debatable. The provisions formulated here are not logically forbidden. But alternative provisions denying the immaterial basis of the world do not seem to be logically forbidden either. Such alternatives that exclude the non-material, super-natural foundation of the world should be called naturalistic arguments. There are these possible naturalistic arguments.

Naturalistic Argument 1. The natural world has no fundamental, ultimate (i. e., groundless) ground. Nevertheless, there exists some ground for everything existing. The chain of grounds is endless. Thus, point 1 of the theistic argumentation scheme is accepted, but points 3 and 4 are not.

Objection to Naturalistic Argument 1. If every chain of grounds is infinite and there is no first ground in it, nothing is grounded either. Anything grounded is infinitely far from an infinitely distant foundation - in this sense, the chain is symmetrical - and the absence of the first ground means the absence of the end of the chain. At least the final link in the chain, with which anything grounded must be identified, is no more explainable than the first link. Thus, the absence of the first ground is equivalent to the absence of anything grounded. There is yet another objection. Even accepting the existence of an infinite chain of grounds, one should admit that one infinite chain is different from another. For this difference, there must be common ground - fundamental for both chains.

Naturalistic Argument 2. The natural world has no foundation. The world as it exists is a "brute fact"; the world is what it is and, therefore, cannot be different. The world (in all its diversity) is the ground of oneself. Therefore, the question of the ultimate foundation is meaningless; the question of grounding does not apply to the world as a whole, only to separate existing objects. This argument denies points 1 and 3 of the theistic argumentation scheme, but in a sense, it recognizes point 4 , identifying groundless ground with the world in all its diversity.

Objection to Naturalistic Argument 2. It rests on the provision that the diversity of the world is concrete. Not all logically and naturally possible facts take place in our world. It is enough to ask oneself whether the existence of another world with a different variety of objects is permissible for the argument under consideration to look doubtful. This material world we live in would have to exist due to absolute contingency if naturalistic argument 2 were still actual. But absolute contingency is impossible. A random fact is a way of realizing different possibilities. There can be no contingency when there is only one possibility, and one can't even presuppose its nonrealization. If something accidental happens, then it is not the only thing that happens. Contingency coexists with alternative possibilities, with the necessity of this (and not another) alternative, and so has some outer ground. Pure contingency, which is nothing more than contingency, does not exist. Such is the case with the absolutely contingent first ground of the material world. Absolute contingency is contingency without any further ground, and therefore it is entirely identical with absolute necessity. Being a concrete variety, the material world does not exist with absolute necessity or, equivalently, is not absolutely contingent.

Naturalistic Argument 3. The natural world is everything that can exist. In other words, everything that can exist exists. If there are alternative possibilities, something is better adapted to existence (a favourite idea of evolutionary biologists, notably R. Dawkins). Such an argument is compatible with point 1 of the theistic argumentation scheme, even with point 4 (all logically and naturally admissible possibilities can be taken as the ultimate ground of what exists). Only point 3 of the above scheme is resolutely denied.

Objection to Naturalistic Argument 3. Suppose the world is all that can exist, and this all is explained without the participation of an external factor. In that case, this totality of the possible necessarily contains mutually exclusive entities. This makes the indicated totality unrealizable. All (alterna- 
tive) possibilities cannot be realized if we are talking about the world as a whole, that is, about everything that exists. There are mutually exclusive possibilities among them. Mutually exclusive possibilities cannot coexist as parallel (possible) worlds since such coexistence is also only one of the possibilities (the unique, the only existing world and one of many worlds that cannot coexist). The choice between them is inevitable, but the choice must have a ground. Neither one of such contradictory entities can play the role of the world's foundation, nor all entities together, since such a primary ground must, in turn, be grounded. The world, therefore, is not all that can exist. Suppose from another point of view; we imagine what really exists as something that has an advantage in existence over its alternatives. In that case, this advantage (as well as any disadvantage) must have an external ground.

Naturalistic argument 4. In the material world, there are fundamental parts (natural structural elements or laws of nature) that are the ground of everything (a favourite idea of physicists dreaming of a Final Physical Theory). This argument does not deny point 1 of the theistic argumentation scheme; it leaves open the question about point 4 (or bypasses it) and, like naturalistic argument 3 , principally rejects point 3.

Objection to Naturalistic Argument 4. When trying to find the fundamental natural parts in the material world or the ultimate physical elements, we must constantly ask why these parts are fundamental? How does their fundamental nature derive from their properties? Why are they like that and are not something different? And do they really not require further explanation and grounding? As a rule, some quite specific and rather complex physical objects or conditions are proposed as such an ultimate ground for everything. It is possible to prove their existence, but it is impossible to prove the absolute necessity of their existence, therefore, their fundamental nature.

For the sake of completeness, agnostic considerations should be added to the anti-theistic arguments. From this perspective, the world is inexplicable because human knowledge is limited and will always be in this position. Perhaps so, although perhaps not. In any case, this does not exclude attempts to explain the world and accept the best explanation achieved.

Let's summarize preliminary results. If the stated objections to naturalistic arguments are correct, then the natural world cannot be explained by itself. The world cannot be explained from its physical (or natural) part. At the same time, the material world cannot but be explained. It requires an explanation by something external to itself.

Of course, this conclusion cannot yet be recognized as the final confirmation of the theistic picture of the world. Negative proof in the logical form of modus tollendo ponens is, in fact, not a direct proof of the existence of God, or at least of some transcendental reality, but is just the proof of the doubtfulness of denying it. Direct arguments seem to have to be formulated anyway. One should supplement the stated general scheme of theistic argumentation by some additional considerations to present such proof.

This is how this extended scheme may look like:

1. Something exists. This means existence in any sense other than negative (the existence of absolute nothingness is excluded). The truth of this statement is evident from all points of view.

2. The existing differs. This statement is also undeniable, being an expression of a basic fact similar to Descartes' famous cogito. It is impossible to exist without being different (which indicates the identity of being and difference (more about this, in [3])).

3. All that exists does not exist without something different from it. It is true since the existing is different and, therefore, there cannot be one thing only within the world.

4. Everything that exists (except for what is in a sense identical to everything that exists) has a ground for its existence in something different from it (in the sense that is expressed in point 1 of the previous scheme). This statement follows from statement 3 - if something (object A) does not exist without something else (object $B$ ), then the existence of another (object $B$ ) is necessary for the existence of this something (object $\mathrm{A}$ ).

5 . The ground is not necessarily inexistent, provided the grounded does not exist. It is so since any existing requires the existence of something else outside itself, but not necessarily something concrete, that is, not necessarily what is called here the grounded. So the grounded is necessarily connected with the ground; the ground is not necessarily connected with the grounded.

6. The grounded generally (with some exclusions) is possible to its ground; that is, it may or 
may not exist if the ground exists. Since the grounded is also the ground to its grounded, it is necessary in relation to the next link in the series of groundings.

7. The existence of something without a ground is necessary. There is a reality that exists with absolute necessity. Since a) something exists and it is an absolute, undeniable fact and b) the grounded is generally only possible, then something without a ground cannot but exist.

8. There is the first (or ultimate) foundation of everything. This first foundation is that which exists independently of everything that may not exist. Thus it is that which exists entirely necessarily. In other words, it does not exist as a realized possibility, though it can exist in something other as a potential necessity.

9. The first ground includes all entities (no matter how many of them there may be, not excluding one entity) which mutually do not exist in the absence of their counterparts. In other words, the ultimate ground includes all necessary entities.

10. The world in which we find ourselves can be called the natural world. But it is better to define it as material. The material world is a world in which there exist (possibly along with others) material objects, that is, terminally individual and concrete objects. The concept of terminal individuality and concreteness must be clarified. An object is terminally individual if it (without its change) does not exist and cannot exist as different objects. An object is terminally concrete if it (without its change) does not exist as an object with additional properties to those that it has. Terminal individual and concrete objects differ, of course, from abstract objects (or formal ones, in other words). The following example nicely illustrates the difference. Imagine an abstract object, say, mathematical (all mathematical objects are abstract) - a triangle. One can imagine many triangles, each of which is a triangle, that is, it is an instance of a general object exemplified in individuals. In this case, more triangles can be added to any finite set of triangles; that is, one can increase the generality of a given mathematical object. Further, you can imagine a triangle rectangular, isosceles, equilateral, relatively large, relatively small, more specific than the original representation. At the same time, one more property can be added to each specific triangle; in other words, it can be concretized even more. So, a triangle as a mathematical (abstract) object can exist as a general object, represented by sin- gle objects, and can, in principle, be infinitely concretized. No material object is capable of this. Imagine a material triangle, for example, a triangle made of blue wire, which I hold in my hands. It cannot exist as different triangles; it cannot be more specific than it is. In this sense, it is entirely terminally individual and concrete. From such objects, the material or natural world consists (entirely or to a large extent).

11. The material world is the world of possible objects. This follows from the fact that any abstract and general objects (as it has been shown) can be instantiated into different terminally concrete and individual objects. Or can be not instantiated. (Whether all abstract objects are necessary entities only, respectively, whether some abstract objects entirely belong to the material world, we will not decide here).

12. Obviously, a) the material world has a foundation; b) the ground of the material world is outside this world, is transcendent to it; c) the ground of the material world is non-material. This statement is based on what has been said before. Note that speaking about finding a transcendent foundation outside the natural world, one should not in any way understand this "outside" in the spatial sense. We are talking about purely existential, metaphysical transcendence, in other words, about the simple difference between the foundation of the world and the world itself or any of its material parts. The difference here acquires the character of the highest metaphysical reality (in a certain sense, let's repeat, it is identical to being).

13. The relationship between the ground and the grounded is the relationship between the reality of possibilities and the possibilities that have been realized. In a sense, the ultimate foundation is the possibility of anything else (it appears to be so if the ultimate foundation is recognized as being identical to metaphysical difference).

14. A possibility that is to be realized cannot be the only one (otherwise, it would be necessary). The ground's necessary transition to the grounded destroys the very status of the ground and the grounded, since instead of the ground and the grounded one has a simple (necessary) coexistence of different realities (objects). The grounded one has a simple (necessary) coexistence of different realities (objects). This coexistence must itself be grounded and therefore is not fundamental. Consequently, the foundation of the world is some alternative possibilities (at least 
such is the ultimate foundation of the material world).

15. All alternative possibilities cannot be realized since there are mutually exclusive possibilities among them. Mutually exclusive possibilities (as already mentioned) cannot coexist as parallel (possible) worlds, which was mentioned when refuting the naturalistic argument 3.

16. An absolute, ultimate foundation cannot include unequal possibilities as well. Since every specific probability distribution of different possibilities requires its ground and a ground containing unequal possibilities is not an ultimate foundation, it must have its further ground.

17. The actualization of what is possible in grounding relation cannot be accidental. This is obvious if one talks about an ultimate (absolute) foundation (in non-fundamental relations of grounding, random results are rather possible). This was also mentioned in the refutation of the naturalistic argument 2 .

18. The described types of transition from the ultimate foundation of everything to the grounded as to the realized possible (that is, to the material world) - namely the necessary transition, the realization of all possibilities, the realization of the preferred possibility, randomness - all these ways of transition are characterized by the directness of the ground / the grounded relation. In this type of grounding, the ground has what is sufficient for the actualization of the grounded or (in the variant of randomness) there are factors (objects) external to the ground, which also directly condition the actualization of the grounded.

19. The invalidity of all direct ways of transition from the ultimate foundation to the possible grounded objects makes real the indirect one. So the difference between the ultimate foundation and the possible grounded objects is not direct. There is a mediator between the ultimate foundation and the possible grounded objects.

20 . The mediator has two sides, which are identified as two differences - from the grounded and the ultimate ground. On the one side, the mediator differs from the grounded as its analogue separated from the grounded itself or as an image of a result of grounding (but not as a result itself). Such an entity can also be called a grounding criterion, an anticipation of a result, or a standard applied to alternative grounding possibilities.
21. The mediator differs, on the other side, from the ultimate foundation of everything as the ground of the transition to specific, grounded objects (or the ground of a specific transition). Such an entity that ensures this transition according to a grounding criterion can be called the source of the transition to the grounded, or it can be called the actor.

22. The difference of the grounding result (mediated by the actor and the anticipation of a result) from its ground should be called activity. Activity has its own ground, in which one can discern the whole ground of the grounded, the actor, the anticipation of a result and the possibilities of the grounded.

23. The ground of activity can be external if the elements of indicated difference are themselves grounded by entities not included in their circle. This is how, for example, the activity of intelligent technical devices is externally grounded. An outwardly conditioned activity is not in some respect the agent's activity; in other words, it is not in some respect an activity conditioned only by the agent (which, therefore, cannot yet be called a subject).

24. In the case of fundamental reality, the ground of activity is internal. Activity is due to the mutual grounding of the elements that form the ground of activity. There are simply no external entities that condition activity since we are talking about everything that exists.

25 . The internally grounded actor differs from the result anticipation, like the anticipation of activity. Such an actor anticipating activity is called the subject of activity. The subject is identical to the actor with anticipation of activity and anticipation of a result, the activity of which is conditioned only by the actor itself and its anticipations. The subject, therefore, is an actor whose activity (at least in a certain respect) is not conditioned by external circumstances. (A human person is a subject since his or her activity in a certain respect is not conditioned by external circumstances).

26. In the subject, two spheres of activity are correlated - ideal (image) and natural (action). The image consists of the formal elements of activity, which constitute the form of consciousness in human beings. The image also includes distinguishing the form of the source of activity, which is analogous to human self-awareness or the human Self. 
27. The subject's activity under these circumstances acquires the nature of choice. This choice is purposeful and free from immediate necessity. It includes the alternative selectable forms, the selection criterion, and the adequate ground for the choice (an actor). The selection criterion coexists with the selectable forms as an exemplary image of the latter. An exemplary image is the direct ground of choice.

28. In general, one can say that the ground of all that exists reproduces the function of choice. This function singles out the subject in the universal ground or, which is the same, singles out the ground of activity. The function of choice is a necessary mediation within the relationship of the ultimate ground and the possible grounded (the material world). This function to the material world acquires the nature of the world subject.

29. An analogy can be drawn between the world subject and a human being since the latter is also a subject. In a person, the ratio of the ideal and natural sides of activity is psycho-physical; it is the relationship between consciousness, cognition and morality on one side and physical action on another. The world subject must be similar to a human person; this subject rather should be a rational and moral being.

30 . In relation to the absolute foundation of everything, the world subject is the first difference of this foundation from itself, the difference between the foundation as the world possibility and its purely existential side. However, relating to the material world, the world subject is already defined as its external foundation, that is, the acting (or active) side of the ultimate foundation of everything. The world subject is the first difference of this foundation from itself to the absolute foundation of everything, the difference between the foundation as the world possibility and its purely existential side. However, relating to the material world, the world subject is already defined as its shallow foundation, the acting (or active) side of the ultimate foundation of everything.

31. The function of choice empowers the world subject with the role of the material world Creator. It also leads to omniscience since conscious creativity requires knowledge of everything that is being done. The presence of an exemplary image of the chosen, the criterion of choice (which posits the choice between good and bad) is expressed by the category of Good and the quality of all-goodness.
32. Eventually, this omnipotent, omniscient, allgood, immaterial rational being mainly corresponds to God of theistic religions. However, it does not cover all the specific features of the images of God drawn by religions.

\section{CONCLUSION}

What has been proven, and to what extent? Has God's existence been substantiated? It seems that absolute thinkability and rationality of the idea of God has been proven. And vice versa - absolute unthinkability of the world without God has been substantiated. Does this mean that God exists? The conclusion can be drawn if desired, but it will not be completely apodictic. To come to an apodictic conclusion, we need, for example, such an inference:

The real existence of God is rationally demonstrable.

There are no explanations other than rational ones of what really exists.

\section{God is necessarily real (God really exists).}

Unfortunately, we lack the big premise of the syllogism. We cannot say with complete certainty that the world is rational. In other words, that it is entirely consistent with our way of thinking. Therefore, only a very significant plausibility of the idea of God and its logical admissibility can be deduced with sufficient logical rigour. One can argue that the idea of God more rationally explains the world. Naturalistic models of the world lead those who are trying to understand the world this way, either to contradictions and discrepancies or to complete uncertainty and inexplicability. Theism, strange as it may sound to many, is more rational than naturalism. Naturalism is a kind of mysticism where the mysterious forces of nature operate. So, it is evident that theism is rational, naturalism (as the principle of the general explanation of everything) is irrational. But the question remains how rational the world is, how rational everything that exists might be.

There is no logical reason not to believe in the existence of God. But there can be (and, apparently, often occur) super-logical grounds for doubt. Doubt is incompatible with faith. Intuition, which finds support in the data of limited, incomplete life experience, speaks in this case in favour of the absence of God around us and in ourselves. Further, this intuitive sense of the absence of God compels the mind to seek rational 
excuses for such intuition. These justifications are based on the particular sciences data, which, like the intuition described, are rationalizations of incomplete, limited experience. So that these scientific constructions could claim to be a metaphysical generalization, a ban is introduced on the recognition of direct reflecting the whole experience in human thinking. As for the lack of complete experience, it should be argued, however, that our experience is dual in this sense. We perceive simultaneously a part of the existing and all that exists. More precisely, we perceive something as part of the existing and as the existing in general. We perceive at once in the object of perception some different levels of abstractness of its being. We find around us and in ourselves something that exists, which, at the same time, is existing as such. Therefore, metaphysics is not a purely speculative construction; it, like any science, relies on experiential data. Besides, we have no reason to distrust our mind as much as Immanuel Kant did in his time.

\section{REFERENCES}

1. Almeida, M. (2018). Cosmological Arguments. Cambridge: Cambridge University Press.

2. Evans, C. S. (2018). Moral Arguments for the Existence of God. The Stanford Encyclopedia of Philosophy (Fall 2018 ed.). Retrieved from https://plato.stanford.edu/archives/fall2018/entries/moral-arguments-god

3. Kulieshov, A. (2019). Nachala metafiziki [The foundations of metaphysics]. Stavropol: Logos (in Russian) [Кулешов, А. (2019). Начала метафизики. Ставрополь: Логос].

4. Oppy, G. (Ed.). (2018). Ontological Arguments. Cambridge: Cambridge University Press.

5. Oppy, G. (2019). Ontological Arguments. In The Stanford Encyclopedia of Philosophy (Spring 2020 ed.). Retrieved from https://plato.stanford.edu/archives/spr2020/entries/ontologicalarguments

6. Ratzsch, D., \& Koperski, J. (2019). Teleological Arguments for God's Existence. In The Stanford Encyclopedia of Philosophy (Summer 2020 ed.). Retrieved from https://plato.stanford.edu/archives/sum2020/entries/teleological-arguments

7. Reichenbach, B. (2021). Cosmological Argument. In The Stanford Encyclopedia of Philosophy (Spring 2021 ed.). Retrieved from https://plato.stanford.edu/archives/spr2021/entries/cosmologicalargument

8. Ritchie, A. (2012). From Morality to Metaphysics: The Theistic Implications of our Ethical Commitments. Oxford: Oxford University Press.

9. Sober, E. (2019). The Design Argument. Elements in the Philosophy of Religion. Cambridge: Cambridge University Press.

10. Walls J., \& Dougherty T. (Eds.). (2018). Two Dozen (or so) Arguments for God. New York: Oxford University Press. 